Keith R. McCrae, MD

Department of Hematology/Oncology, Taussig

Cancer Institute, and Department of Cardiovascular

and Metabolic Sciences, Lerner Research Institute,

Cleveland Clinic, Cleveland, $\mathrm{OH}$

\title{
Thrombotic thrombocytopenia due to SARS-CoV-2 vaccination
}

\section{Published May 5, 2021}

\section{ABSTRACT \\ Vaccine-induced thrombotic thrombocytopenia (VITT) has been reported after vaccination with the AztraZeneca ChAd0x1 nCoV-19 and the Johnson and Johnson Ad26. COV2.S vaccines. This manuscript provides a brief over- view of reported cases, clinical and laboratory features, and current understanding of the pathogenesis of VITT. The author also poses unananswered questions and identifies directions for future study.}

\section{INTRODUCTION}

The global SARS-CoV-2 pandemic has resulted in more than 150 million confirmed infections and 3 million deaths (https://covid19.who.int). The scope of the pandemic has led to an unprecedented effort to develop effective vaccines. Currently, 3 vaccines have received US Food and Drug Administration emergency use authorization (EUA): the messenger RNA (mRNA)-based vaccines produced by Moderna (mRNA-1273) and Pfizer-BioNTech (BNT162b2), and the adenoviral-based vaccine from Johnson and Johnson (J\&J; Ad26.COV2.S). These vaccines, as well as the adenoviral vaccine $\mathrm{ChAdOx} 1 \mathrm{nCoV}-19$ from AstraZeneca (AZD1222), are also authorized for use in Europe (Table 1). As of this writing, at least 133 million people in the United States have been vaccinated with a SARS-CoV-2 vaccine, and continued vaccination will play a critical role in controlling COVID-19.
The statements and opinions expressed in COVID-19 Curbside Consults are based on experience and the available literature as of the date posted. While we try to regularly update this content, any offered recommendations cannot be substituted for the clinical judgment of clinicians caring for individual patients.

doi:10.3949/ccjm.88a.ccc078

\section{KEY FEATURES OF VACCINE-INDUCED THROMBOTIC THROMBOCYTOPENIA}

\section{Who is affected}

Recently, several reports have documented the occurrence of a post-vaccination syndrome that has become known as vaccine-induced thrombotic thrombocytopenia (VITT). ${ }^{1-4}$ This syndrome has been described as occurring 5 to 24 days after vaccination with the ChAdOx1 nCoV-19 vaccine, and characterized by thrombocytopenia accompanied by thrombosis, often at unusual sites. After a report of an additional case occurring after immunization with the $\mathrm{Ad} 26$. COV2.S vaccine, ${ }^{4}$ review of Ad26.COV2.S clinical trial data revealed an additional 5 cases of VITT. ${ }^{5}$ Of the approximately 46 cases reported in the literature to date, 40 have relatively detailed patient history and demographic information ${ }^{1-5} ; 28$ have occurred in females ranging in age from 21 to 77 (though most commonly under age 50), and only a few of these patients have been on estrogen therapy.

\section{Clinical and laboratory features}

Severe thrombocytopenia with platelet counts below $10 \times 10^{9} / \mathrm{L}$ have been reported, though median nadir platelet counts are generally in the range of 20 to 30 $\times 10^{9} / \mathrm{L}$. Some patients, however, have demonstrated only mild thrombocytopenia. A predilection for cerebral venous sinus thrombosis (CVST) is common, occurring in 27 of 40 patients. Splanchnic thrombosis is also frequent, particularly involving the portal vein. The reasons underlying the localization of venous thrombi to these uncommon sites is unknown. In addition to venous thrombi, arterial thromboembolism, including aortoiliac thrombosis and stroke, has occurred in less than $10 \%$ of patients. ${ }^{2,3}$

From a laboratory perspective, high levels of D-dimers have been reported in most patients with VITT, and in some patients have levels more than 
TABLE 1

\section{Current SARS-CoV-2 vaccines}

\begin{tabular}{|c|c|c|c|c|c|}
\hline Vaccine & Nomenclature & Type/vector & Antigen & US approval & European approval \\
\hline Moderna & mRNA-1273 & $\begin{array}{l}\text { mRNA in lipid } \\
\text { nanoparticles }\end{array}$ & $\begin{array}{l}\text { Stabilized, prefusion } \\
\text { spike protein }\end{array}$ & $\begin{array}{l}\text { Emergency Use Au- } \\
\text { thorization (EUA) }\end{array}$ & $\begin{array}{l}\text { Conditional Market- } \\
\text { ing Authorisation } \\
\text { (CMA) }\end{array}$ \\
\hline Pfizer-BioNTech & $\begin{array}{l}\text { BNT162b2 (EU- } \\
\text { Cominarty) }\end{array}$ & $\begin{array}{l}\text { mRNA in lipid } \\
\text { nanoparticles }\end{array}$ & $\begin{array}{l}\text { Stabilized, prefusion } \\
\text { spike protein }\end{array}$ & EUA & CMA \\
\hline $\begin{array}{l}\text { Johnson \& Johnson/ } \\
\text { Janssen }\end{array}$ & Ad26.COV2-S & $\begin{array}{l}\text { Adenovirus } 26 \text { (spe- } \\
\text { cies A) }\end{array}$ & $\begin{array}{l}\text { Stabilized, prefusion } \\
\text { spike protein }\end{array}$ & EUA & CMA \\
\hline Astra-Zeneca & $\begin{array}{l}\text { ChAd0x1 nCoV19 } \\
\text { (AZD1222, Vaxzevria) }\end{array}$ & $\begin{array}{l}\text { Chimpanzee adenovi- } \\
\text { rus (species E) }\end{array}$ & $\begin{array}{l}\text { Unmodified spike } \\
\text { protein }\end{array}$ & - & CMA \\
\hline
\end{tabular}

100 times higher than laboratory normal cutoffs. ${ }^{2,3}$ Decreased fibrinogen levels, elevated D-dimer, and prolongation of the international normalized ratio consistent with the International Society on Thrombosis and Haemostasis criteria for overt disseminated intravascular coagulation (DIC) are present in at least one-half of patients, although evidence of a consumptive coagulopathy that does not meet strict DIC criteria are present in most.

These findings are consistent with an analysis of ChAdOx1 nCoV-19-vaccinated patients by the UK Medicines and Healthcare Products Regulatory Agency (MHRA) (https://www.gov.uk/government/ news/mhra-issues-new-advice-concluding-a-possiblelink-between-covid-19-vaccine-astrazeneca-andextremely-rare-unlikely-to-occur-blood-clots), which has reviewed 79 cases of VITT; 44 of these were characterized by CVST and thrombocytopenia, and 35 as thromboses in other veins; 51 of these cases were in women.

VITT is associated with a significant death rate, with at least 16 of 40 reported patients dying, most commonly of cerebral edema or bleeding secondary to extensive CVST. The rate of death was lower (19 of 79) in the MHRA analysis. It is not known whether any of the patients with VITT in this series have previous COVID-19.

\section{SIMILARITIES WITH HEPARIN-INDUCED THROMBOCYTOPENIA AND THROMBOSIS}

Heparin-induced thrombocytopenia with thrombosis (HITT) is a highly prothrombotic disorder caused by antibodies to platelet factor 4 (PF4)-heparin complexes; these antibodies appear 5 to 14 days after heparin exposure. HITT antibodies are directed toward a neoepitope on the highly cationic PF4 that is exposed after charge-dependent binding to heparin or a related anionic glycosaminoglycan or polyanion. When PF4 and heparin are present at the proper stoichiometric concentration (approximately 1:1 for unfractionated heparin), ultralarge, highly antigenic complexes that are recognized by HITT antibodies may develop. ${ }^{6}$ These antibodies cause activation of platelets and monocytes through binding of these complexes through Fc gamma receptor II, and may also activate endothelial cells through binding to PF4 associated with negatively charged endothelial cell glycosaminoglycans. ${ }^{\text {? }}$

The occurrence of aggressive thrombosis and thrombocytopenia in SARS-CoV-2-vaccinated patients suggested similarities between VITT and HITT and led investigators to test patients for the presence of antibodies to PF4-heparin complexes. Antibodies to complexes of heparin or heparinlike polyanions (used in commercial enzyme-linked immunosorbent assay kits) bound to PF4 were observed in all patients with VITT, despite no recent exposure of these patients to heparin. ${ }^{8}$ Moreover, like HITT antibodies, sera and purified PF4-heparin antibodies from VITT patients caused platelet activation in a PF4-dependent manner. However, in contrast to HITT, activation of platelets by VITT sera was not enhanced in the presence of low heparin concentrations, suggesting subtle differences in the nature of the target epitope.

Taken together, the serologic and platelet studies observed in patients with VITT resemble those described in "autoimmune" HITT (aHITT), an uncommon HITT variant that encompasses several unusual syndromes including delayed-onset HITT, persisting HITT, spontaneous HITT, and severe HITT with DIC. ${ }^{9}$ In several of these disorders, there is no history of recent heparin exposure, and it is 
believed that binding of antibodies to complexes of PF4 bound to related polyanions such as hypersulfated chondroitin sulfate, DNA, RNA, polyphosphate, or bacterial-wall components may result in a structural change in PF4 that exposes an antigenic neoepitope. In the case of VITT, it has been postulated that DNA may serve as the polyanion that binds $\mathrm{PF} 4,{ }^{2}$ but this remains speculative, and the underlying mechanisms by which antigenic polyanion-PF4 complexes form in VITT remains to be determined.

\section{DIAGNOSIS AND MANAGEMENT}

Despite the high initial mortality associated with VITT, prompt recognition and institution of specific therapy will likely lead to better outcomes. International agencies and societies including the American Society of Hematology (ASH) (https://www. hematology.org/covid-19) and International Society of Thrombosis and Hemostasis (ISTH) ${ }^{10}$ have issued recommendations on diagnosis and management. A brief summary follows.

\section{Diagnostic criteria}

Key criteria for the diagnosis of VITT include the following:

- The patient has received the $\mathrm{ChAdOx} 1 \mathrm{nCoV}$ 19 or Ad26.SOV2.S vaccine within the last 30 days.

- Thrombocytopenia that is generally moderate to severe (platelet count $<50 \times 10^{9} / \mathrm{L}$ ), though in some cases it is mild, particularly in the early stage of VITT.

- Thrombosis, often involving the cerebral venous sinus or splanchnic veins. Arterial thrombosis occurs less commonly. Physicians should be aware of the clinical presentations of these events, which include severe, nonrelenting headache in CVST, and abdominal or back pain (or both) and nausea and vomiting in splanchnic thrombosis.

- Anti-PF4-heparin or PF4-polyanion antibodies, or both, assessed using a commercially approved assay. However, some rapid immunoassays and chemiluminescence assays have yielded falsenegative results. ${ }^{3}$ ISTH guidelines recommend confirmation using a functional assay such as carbon 14-labeled serotonin release assay.

\section{Initial evaluation, and the differential diagnosis}

The initial evaluation of suspected VITT should include a complete blood cell count, D-dimer and fibrinogen levels, PF4-polyanion ELISA, and imaging studies appropriate for the diagnosis of thrombosis and as dictated by symptoms.

On the surface, the diagnosis of VITT would seem relatively straightforward. However, multiple cases of immune thrombocytopenia have been described after SARS-CoV-2 vaccination, including after the Moderna and Pfizer vaccines. ${ }^{11}$ Likewise, anti-PF4 antibodies are seen in a variety of clinical situations, such as after cardiovascular surgery, and are seen even in normal individuals, but these alone do not make the diagnosis of VITT.

\section{Cornerstones of treatment}

Treatment of VITT should be suggested by the clinical and laboratory findings outlined in Table 2. However, other potential scenarios should be considered on a case-by-case basis.

The cornerstones of treatment of VITT are intravenous immunoglobulin, usually given at a dose of 1 $\mathrm{gm} / \mathrm{kg}$ for 2 days, and anticoagulation. The mechanism of intravenous immunoglobulin is presumed to be Fc gamma receptor blockade, similar to that observed in HITT, resulting in a rapid rise in the platelet count.

Although heparin has not been definitively shown to worsen outcomes, it should be avoided in patients with VITT. Nonheparin anticoagulants such as direct oral anticoagulants and argatroban are preferred, and danaparoid has been recommended in settings outside the United States.

Platelet transfusion may worsen thrombotic manifestations of VITT and should be avoided, except perhaps in the setting of life-threatening bleeding.

\section{UNANSWERED QUESTIONS, DIRECTIONS FOR FUTURE INVESTIGATION}

We do not yet know why VITT antibodies develop after SARS-CoV-2 vaccination. To date, VITT has developed only in patients who have received the ChAdOx1 nCoV-19 and Ad26.COV2.S vaccines, both of which employ an adenoviral vector. This has led to speculation that the adenoviral component of the vaccine may be responsible.

However, the two vaccines are built upon different vectors, the Ad26.COV2.S vaccine on an adenovirus 26 vector (Ad species $A$ ), and the $\mathrm{ChAdOx} 1 \mathrm{nCoV}$ 19 on a chimpanzee adenovirus vector (Ad species E). These use different receptors to gain cellular entry and likely have different biological characteristics. Moreover, the nature of the spike protein encoded by both vectors differs as well, with the Ad26.COV2 construct encoding a membrane-bound spike protein 
TABLE 2

\section{Indications for initiating treatment of suspected VITT}

Thrombocytopenia and a positive PF4-polyanion test in the presence of thrombosis

High clinical suspicion of VITT based on the presence of thrombosis and thrombocytopenia after vaccination, even when PF4-polyanion ELISA results are pending

Thrombocytopenia and a positive PF4-polyanion ELISA, with or without a very high or increasing D-dimer level, even in the absence of thrombosis

ELISA = enzyme-linked immunosorbent assay; VITT = vaccine-induced thrombotic thrombocytopenia

stabilized by two proline substitutions that does not shed the S1 fragment of the spike protein, whereas ChAdOx1 nCoV-19 encodes an unmodified S protein.

Interestingly, high-titer anti-PF4-heparin antibodies may occur in COVID-19, but these do not activate platelets, suggesting differences from VITT antibodies that have yet to be defined..$^{12}$ Likewise, IgG fractions from some patients with COVID-19 have been shown to induce Fc gamma receptor IIdependent platelet apoptosis, although the nature of these antibodies or immune complexes is unknown. ${ }^{13}$

Other unanswered questions include the risk of revaccination, the significance of PF4 antibodies that may develop after natural SARS-CoV-2 infection, and the patient characteristics that predispose to VITT.

Finally, the incidence of VITT must be viewed in comparison to a CVST incidence of 0.22 to 1.57 cases per 100,000 per year in the general population, which does not differ substantially from the incidence in vaccinated patients, which is estimated at 1 per 100,000 to 1 per $1,000,000$ individuals. ${ }^{8}$ While this low incidence represents a challenge to the study of patients with VITT, it provides reassurance of the safety of SARS-CoV-2 vaccination relative to the incidence and outcomes of COVID-19 disease.

\section{DISCLOSURES}

The authors report no relevant financial relationships which, in the context of their contributions, could be perceived as a potential conflict of interest.

\section{REFERENCES}

1. Schultz $\mathbf{N H}$, Sørvoll $\mathbf{I H}$, Michelsen $\mathbf{A E}$, et al. Thrombosis and thrombocytopenia after ChAdOx1 $\mathrm{nCoV}-19$ vaccination [published online ahead of print, 2021 Apr 9]. N Engl J Med 2021; 10.1056/ NEJMoa2104882. doi:10.1056/NEJMoa2104882

2. Greinacher A, Thiele T, Warkentin TE, Weisser K, Kyrle PA, Eichinger S. Thrombotic thrombocytopenia after ChAdOx1 nCov-19 vaccination [published online ahead of print, 2021 Apr 9]. N Engl J Med 2021; 10.1056/NEJMoa2104840. doi:10.1056/NEJMoa2104840

3. Scully M, Singh D, Lown R, et al. Pathologic antibodies to platelet factor 4 after ChAdOx1 nCoV-19 vaccination [published online ahead of print, 2021 Apr 16]. N Engl J Med 2021; 10.1056/NEJMoa2105385. doi:10.1056/NEJMoa2105385

4. Muir KL, Kallam A, Koepsell SA, Gundabolu K. Thrombotic thrombocytopenia after Ad26.COV2.S vaccination [published online ahead of print, 2021 Apr 14]. N Engl J Med 2021; 10.1056/ NEJMc2105869. doi:10.1056/NEJMc2105869

5. Sadoff J, Davis K, Douoguih M. Thrombotic thrombocytopenia after Ad26.COV2.S vaccination - response from the manufacturer [published online ahead of print, 2021 Apr 16]. N Engl J Med 2021; 10.1056/NEJMc2106075. doi:10.1056/NEJMc2106075

6. Rauova L, Poncz M, McKenzie SE, et al. Ultralarge complexes of PF4 and heparin are central to the pathogenesis of heparin-induced thrombocytopenia. Blood 2005; 105(1):131-138. doi:10.1182/ blood-2004-04-1544

7. Greinacher A. Heparin-induced thrombocytopenia. N Engl J Med 2015; 373(19):1883-1884. doi:10.1056/NEJMc1510993

8. Cines DB, Bussel JB. SARS-CoV-2 vaccine-induced immune thrombotic thrombocytopenia [published online ahead of print, 2021 Apr 16]. N Engl J Med 2021; 10.1056/NEJMe2106315. doi:10.1056/ NEJMe2106315

9. Greinacher A, Selleng $\mathbf{K}$, Warkentin TE. Autoimmune heparininduced thrombocytopenia. J Thromb Haemost 2017; 15(11):2099 2114. doi:10.1111/jth.13813

10. Nazy I, Sachs UJ, Arnold DM, et al. Recommendations for the clinical and laboratory diagnosis of vaccine-induced immune thrombotic thrombocytopenia (VITT) for SARS-CoV-2 infections: communication from the ISTH SSC Subcommittee on Platelet Immunology [published online ahead of print, 2021. https://doi.org/10.1111/ jth. 15341

11. Lee EJ, Cines DB, Gernsheimer T, et al. Thrombocytopenia following Pfizer and Moderna SARS-CoV-2 vaccination. Am J Hematol 2021; 96(5):534-537. doi:10.1002/ajh.26132

12. Brodard J, Kremer Hovinga JA, Fontana P, Studt JD, Gruel Y, Greinacher A. COVID-19 patients often show high-titer non-plateletactivating anti-PF4/heparin IgG antibodies. J Thromb Haemost 2021; 19(5):1294-1298. doi:10.1111/jth.15262

13. Althaus K, Marini I, Zlamal J, et al. Antibody-induced procoagulant platelets in severe COVID-19 infection. Blood 2021; 137(8):10611071. doi:10.1182/blood.2020008762

Correspondence: Keith R. McCrae, MD, Departments of Hematology Oncology and Cell Biology, Health Science-John Sherwin Research, NC10, Cleveland Clinic, 2123 East 96th Street, Cleveland, OH 44195; mccraek@ccf. org 